\title{
Can more invasive procedures be avoided in patients with intrathoracic goitre? Patients with intrathoracic goitre and surgery.
}

\author{
Menduh Oruç ${ }^{*}$, Funda Öz1 ${ }^{1}$ Atilla Durkan², Refi Ülkü ${ }^{1}$ \\ ${ }^{1}$ Department of Thoracic Surgery, Dicle University Medical School, Diyarbakir, Turkey \\ ${ }^{2}$ Department of Thoracic Surgery, Gazi Yaşargil medical school, Diyarbakır, Turkey
}

\begin{abstract}
Objective: We aimed to evaluate whether patients require an incision other than the neck incision before thyroid surgery.

Methods: We analysed data from 30 patients who underwent surgery for retrosternal goitre in our clinic between January 1996 and May 2017. We evaluated patient age, sex, physical examination findings, laboratory results, the surgical technique used, and complications. We used radiography, neck ultrasonography, and thoracic Computed Tomography (CT) to diagnose retrosternal goitre. All patients underwent fine-needle aspiration biopsy and those who were euthyroid underwent surgery. We examined postoperative morbidity, complications, and the duration of hospitalisation.

Results: This study involved 30 patients ( 23 females, 7 males; average age, 44 y (range: 32-69 y)). One undiagnosed event appeared as an intrathoracic mass on thoracic CT; sternotomy was performed and postoperative examination revealed thyroid pathology. Three patients underwent surgery that began with a collar incision and involved complete sternotomy, and three patients underwent partial sternotomy. The duration of hospitalisation for patients in whom the collar incision was sufficient was about $3 \mathrm{~d}$; in cases of partial sternotomy, it was $5 \mathrm{~d}$. The duration of hospitalisation in cases of complete sternotomy was $5.2 \mathrm{~d}$. Infection occurred in three patients and haemorrhage occurred in two patients in the neck incision area; there were no deaths. According to postoperative pathological examination, one patient had Hashimoto's thyroiditis and all other patients had multinodular goitre.

Conclusions: Median Sternotomy (MS) is not necessary in all cases of intrathoracic goitre that extend beyond the thoracic inlet. Thorough preoperative evaluation and good surgical planning are required to avoid unnecessary MS.
\end{abstract}

Keywords: Goitre, Sternum, Thyroid.

Accepted on January 22, 2018

\section{Introduction}

Intrathoracic Goitre (ITG), characterised by abnormal enlargement of the thyroid, is seen in $5 \%$ of the population. In ITG, the thyroid grows slowly but occupies space in the chest cavity [1-4]. The disease can be classified as true (primary) ITG, which is rare ( $1 \%$ of cases) and has no connection with the cervical thyroid tissue, or as secondary ITG ( $99 \%$ of cases), in which the thyroid tissue extends from the neck to the superior mediastinum in the facial plane $[1,4,5]$. In this study, we examined these conditions and surgical approaches to their treatment, with consideration of morbidity and the duration of hospitalisation.

\section{Materials and Methods}

This retrospective study was approved by our institutional ethics committee, and informed consent was waived. We analysed data from 30 patients who underwent surgery for retrosternal goitre in our clinic between January 1996 and May 2017. The patients were informed about their condition. We evaluated patient age, sex, physical examination findings, laboratory results, the surgical technique used, and complications. Most patients presented at our clinic due to neck masses. On thoracic Computed Tomography (CT), thyroid tissue was detected in the thorax, extending downward and behind the sternum from the superior inlet to the mediastinum. In one patient, the mass was not associated with the thyroid; a study of goitre neovascularisation performed via intravenous contrast-enhanced CT showed that it was an intrathoracic mass. During physical examination, we palpated the upper pole of the cervical thyroid, but we could not palpate the lower pole; we thus were cognisant that it extended into the thorax. The diagnosis was supported by radiography, neck ultrasonography, CT, and scintigraphy. Preoperatively, we evaluated all patients' laboratory results and thyroid hormone values. Patients who were euthyroid underwent surgery. 
A member of the general surgical team began each operation with a collar incision and binding of each inferior thyroid artery branch. Care was taken to avoid damage to the recurrent laryngeal nerve. We proceeded to complete or partial sternotomy when we could not dissect the lower pole of the thyroid, which was determined by palpation to extend downward to the mediastinum.

\section{Results}

Data from 30 patients with ITG (23 (76.7\%) females, 7 (23.3\%) males; mean age, 44.43 years (range: 32-69 y)) were evaluated retrospectively. Their presenting complaints included chest pain, swelling of the neck, and dyspnoea (Table 1). Physical examination revealed neck oedema.

In total, $10(33.3 \%)$ cases of ITG were in the left lobe, 13 $(43.3 \%)$ cases were in the right lobe, $6(20 \%)$ cases were bilateral, and 1 case was limited to the mediastinum (Figure 1). The largest mass measured $15 \times 4 \times 5 \mathrm{~cm}$ and the smallest mass measured $7 \times 7 \times 3 \mathrm{~cm}$. In 29 patients, surgery began with a collar incision. Three (10\%) surgeries each continued with Median Sternotomy (MS) and partial sternotomy due to insufficiency of the collar incision. One surgery did not begin with a collar incision; it consisted only of MS, and pathological thyroid tissue was detected.



Figure 1. Primary intrathoracic goiter tomography and its own image.

We examined the vertebral projection of the masses by calculating the ratio of mass length under the thoracic inlet to the total thyroid tissue length (on thoracic CT images and, in some cases, radiographs; Figures 2 and 3 and Table 2). No patient died. One $(3.3 \%)$ patient developed infection in the sternotomy area. In two $(6.6 \%)$ patients, haemorrhage occurred in the collar incision area. One patient developed hoarseness, which was resolved with dexamethasone (Table 3).

The duration of hospitalisation for patients in whom the collar incision was sufficient was $3.08 \mathrm{~d}$; in cases of partial sternotomy, it was $5 \mathrm{~d}$. The duration of hospitalisation in cases of complete sternotomy was $5.2 \mathrm{~d}$ (Table 2). According to postoperative pathological analysis, 1 (3.3\%) patient had Hashimoto's thyroiditis, $27(90 \%)$ patients had benign multinodular goitre, and $2(6.6 \%)$ patients had thyroid adenoma. The duration of postoperative drain use was $3 \mathrm{~d}$.

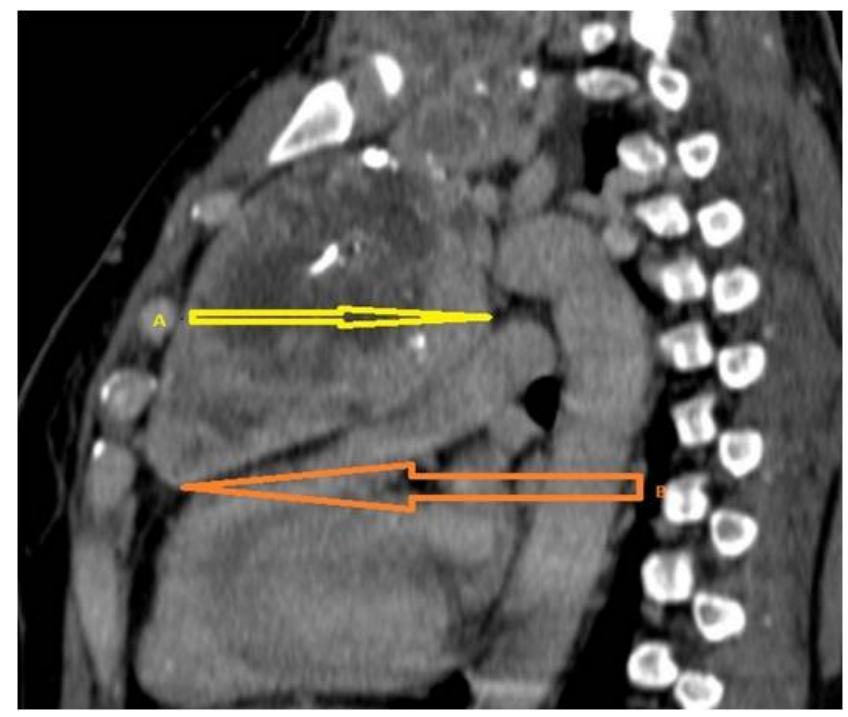

Figure 2. Transverse and longitudinal measurements of thyroid tissue seen on tomography. Orange arrow: longitudinal measurement corresponding to the projection of the vertebrae; Yellow arrow: transverse measurement.

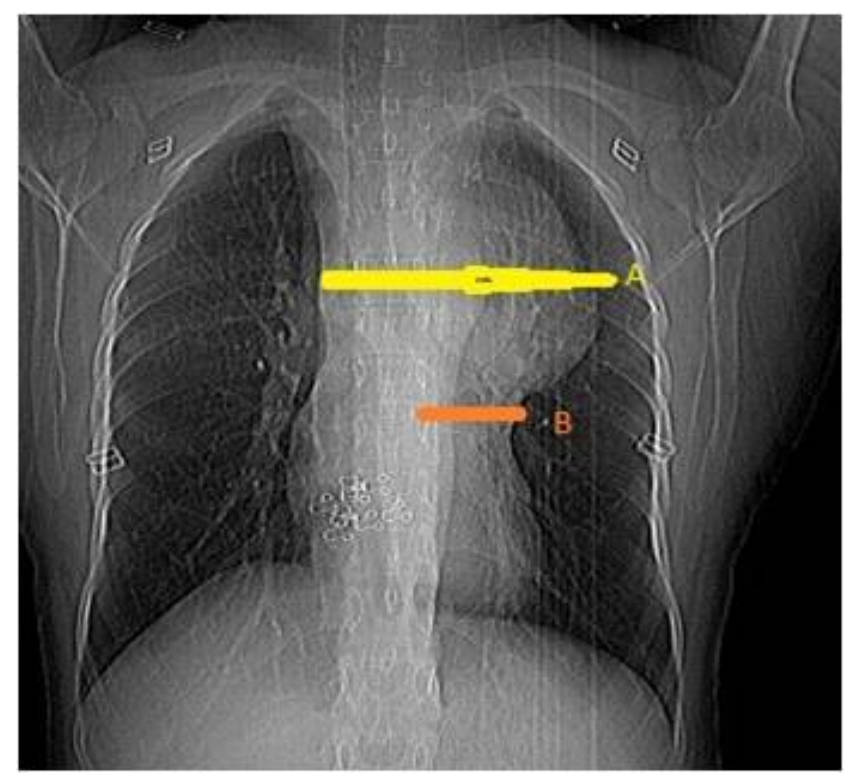

Figure 3. Transverse and longitudinal measurements of thyroid tissue seen on $X$-ray.

Table 1. Symptoms.

\begin{tabular}{lll}
\hline & Event & Rate (\%) \\
\hline Chest repletion & 8 & 22.2 \\
\hline Chest pain & 21 & 58.3 \\
\hline Hoarseness & 1 & 5.5 \\
\hline
\end{tabular}


Can more invasive procedures be avoided in patients with intrathoracic goitre? Patients with intrathoracic goitre and surgery

\begin{tabular}{lll}
\hline Compression to jugular vein & 1 & 2.7 \\
\hline No symptom & 9 & 25 \\
\hline Dysphadia & 4 & 11.1 \\
\hline
\end{tabular}

\begin{tabular}{lll}
\hline Dyspnoea & 5 & 13.8 \\
\hline Syncope attact & 3 & 8.3 \\
\hline
\end{tabular}

Table 2. Clinic features.

\begin{tabular}{|c|c|c|c|c|c|c|c|c|}
\hline Number & Age & Gender & Diameter & X-ray & $\mathrm{Cl}$ & MS & PS & DSH \\
\hline 1 & 34 & Female & 12 & $4^{\text {th }}$ thoracic level & + & + & - & 6 \\
\hline 2 & 35 & Female & 8 & Under $4^{\text {th }}$ thoracic level & + & + & - & 5 \\
\hline 3 & 43 & Male & 8 & $1^{\text {st }}$ thoracic level & + & - & - & 3 \\
\hline 4 & 54 & Female & 7 & $3^{\text {rd }}$ thoracic level & + & - & - & 4 \\
\hline 5 & 51 & Female & 6 & $2^{\text {nd }}$ thoracic level & + & - & - & 3 \\
\hline 6 & 53 & Male & 15 & $3^{\text {rd }}$ thoracic level & + & - & + & 4 \\
\hline 7 & 32 & Female & 10 & $3^{\text {rd }}$ thoracic level & + & - & - & 3 \\
\hline 8 & 41 & Female & 8 & $2^{\text {nd }}$ thoracic level & + & - & - & 3 \\
\hline 9 & 44 & Female & 7 & $3^{\text {rd }}$ thoracic level & + & - & - & 3 \\
\hline 10 & 39 & Female & 11 & $2^{\text {nd }}$ thoracic level & + & - & - & 3 \\
\hline 11 & 41 & Female & 10 & $2^{\text {nd }}$ thoracic level & - & + & - & 5 \\
\hline 12 & 45 & Female & 11 & $2^{\text {nd }}$ thoracic level & + & - & - & 3 \\
\hline 13 & 46 & Male & 9 & $3^{\text {rd }}$ thoracic level & + & - & - & 2 \\
\hline 14 & 35 & Female & 12 & $4^{\text {th }}$ thoracic level & + & + & - & 4 \\
\hline 15 & 32 & Female & 7 & $2^{\text {nd }}$ thoracic level & + & - & - & 6 \\
\hline 16 & 36 & Female & 8 & $1^{\text {st }}$ thoracic level & + & - & - & 3 \\
\hline 17 & 38 & Male & 7 & $1^{\text {st }}$ thoracic level & + & - & - & 5 \\
\hline 18 & 37 & Female & 11 & $2^{\text {nd }}$ thoracic level & + & - & - & 4 \\
\hline 19 & 58 & Female & 9 & $2^{\text {nd }}$ thoracic level & + & - & - & 4 \\
\hline 20 & 57 & Male & 13 & $3^{\text {rd }}$ thoracic level & + & - & + & 7 \\
\hline 21 & 48 & Female & 7 & $4^{\text {th }}$ thoracic level & + & - & - & 2 \\
\hline 22 & 41 & Male & 8 & $2^{\text {nd }}$ thoracic level & + & - & - & 2 \\
\hline 23 & 42 & Female & 7 & $2^{\text {nd }}$ thoracic level & + & - & - & 4 \\
\hline 24 & 46 & Female & 10 & $1^{\text {st }}$ thoracic level & + & - & - & 2 \\
\hline 25 & 41 & Female & 13 & $3^{\text {rd }}$ thoracic level & + & - & + & 4 \\
\hline 26 & 39 & Female & 9 & $3^{\text {rd }}$ thoracic level & + & - & - & 3 \\
\hline 27 & 39 & Male & 7 & $2^{\text {nd }}$ thoracic level & + & - & - & 3 \\
\hline 28 & 41 & Female & 7 & $2^{\text {nd }}$ thoracic level & + & - & - & 2 \\
\hline 29 & 69 & Female & 7 & $2^{\text {nd }}$ thoracic level & + & - & - & 2 \\
\hline 30 & 68 & Female & 7 & $3^{\text {rd }}$ thoracic level & + & - & - & 2 \\
\hline
\end{tabular}

Diameter: Transverse diameter of thyroid under thoracic inlet; X-ray: Projection of Longitudinal length of thyroid; MS: median sternotomy; PS: partial sternotomy; DSH: duration of stay in hospital. 


\section{Discussion}

ITG is generally seen in patients aged $\geq 50 \mathrm{y}$, and it is four times more common in women. It appears as extension of the cervical thyroid tissue to the superior mediastinum, a process aided by gravity [2-4]. ITG can be defined in four ways; by descent from the neck to the thoracic inlet, by extension of the mass to the level of the aortic arch, by radiographic examination, and by detection of the mass at a thoracic vertebra. It can also be defined as the location having more than $50 \%$ of the thyroid mass below the thoracic inlet [6]. In all of our cases, more than $50 \%$ of the thyroid mass was located below the thyroid inlet. Four cases were at the level of the aortic arch, at or below the level of the fourth thoracic vertebra. In one of these cases, the blood supply was completely mediastinal. In the remaining cases, the average transverse diameter below the manubrium was $8.91 \mathrm{~cm}$ (range: $6-15 \mathrm{~cm}$ ), and the average length in the vertebral direction (T1-T4) was 2 thoracic. Lung X-rays showed continuous opacity in the upper cervical region and large mediastinal masses at the lateral deviation of the trachea. On cervical and thoracic CT, mediastinal masses are interpreted as retrosternal thyroid masses associated with adjacent structures in the neck or chest cavity. Intravenous contrast-enhanced CT with a goitre neovascularisation study provides important guidance for surgery for ITG. Cases with normal thyroid supply and venous drainage can be controlled in the neck. The diagnosis is supported by magnetic resonance imaging and scintigraphy when necessary [7-9].

Table 3. Complication according to surgical procedure.

\begin{tabular}{|c|c|c|c|}
\hline & Coller incision & $\begin{array}{l}\text { Coller } \\
+ \text { Sternotomy }\end{array}$ & incision \\
\hline Wound enfectious & 2 & 1 & \\
\hline \multicolumn{4}{|l|}{ Nerve injury } \\
\hline Hemorrhage & 2 & & \\
\hline Pain & 13 & 8 & \\
\hline Pneumonia & & 1 & \\
\hline Termination of drain (d) & 3 & 3 & \\
\hline Mortality & & & \\
\hline
\end{tabular}

When ITG exerts pressure on the surrounding tissues and organs, it may cause symptoms such as shortness of breath, difficulty in swallowing, and syncope due to the compression of vascular structures; it may also be asymptomatic $[2,4,10,11]$. Cervical neck dissection is usually a sufficient approach for ITG. For very large masses, a suture can be placed in the subpolar thyroid region for transport out of the thoracic inlet. If successful, a collar incision is sufficient and no additional surgery is required. However, forcible dissection should be avoided when the lower pole is inflamed, as it can rupture the pleura, inducing pneumothorax. In the worst case, the inferior thyroid gland can rupture and massive bleeding can occur. Dissection is intended to address the upper part of the thyroid; blunt dissection may miss the subpolar region, which makes binding of the blood vessels difficult. In cases with large masses, and in which difficulty in revealing the lower pole is encountered, MS is required to reveal the lower part of the thyroid $[4,5,12]$. MS is also required for the treatment of other conditions in which the thyroid gland extends below the aortic level, i.e. past the carina level, and when the transverse diameter exceeds $10 \mathrm{~cm}$ [7]. Comprehensive preoperative examination enables determination of whether MS is required [13]. In eight of our cases, the transverse diameter of the thyroid exceeded $10 \mathrm{~cm}$, which made access to the lower pole of the mass difficult because it prevented access to the base of the thoracic inlet. Where the collar incision is insufficient, more invasive surgery may be avoided by cutting the clavicle or dislocating the joint to increase the thoracic inlet area [14-16].

In two cases, we increased the area of intervention by dislocating the joints with the help of retractors, without cutting the clavicle, to reach the lower part of the clavicle. In one study, the authors recommended a bipolar approach with cervicotomy and partial upper sternotomy [7]. MS or thoracotomy becomes compulsory when the mass cannot be removed completely, especially in cases involving giant thyroid masses [7,8]. Partial sternotomy was used in three cases in this study due to transverse growth of the mass beyond the thoracic inlet, and longitudinal growth below this level. As these three masses (one of which was primary ITG) were located at or below the level of the aortic arch, we used complete MS. A comprehensive preoperative review, determination of the appropriate surgical field, and good surgical planning are required to prevent unnecessary MS attempts. MS is required for the treatment of mediastinal thyroid conditions, such as ectopic goitre, especially when the mass extends to the T4 vertebra or below the aortic arch, thereby not affording a sufficient area for control of bleeding. Partial sternotomy, instead of complete MS, may be sufficient to avoid bleeding complications of ITG surgery with a tendency to transverse growth that extends beyond the thoracic inlet, but does not reach the T4 vertebra or extend below the carina. MS is an invasive surgical approach that usually increases morbidity and the duration of hospitalisation; it should be avoided whenever possible. All feasible surgical approaches other than partial or complete MS should be attempted after a collar incision has been made. When bleeding is a risk, partial sternotomy can be performed where possible. Unnecessary MS can lead to the development of major complications following subsequent cardiac or mediastinal surgery.

As any study, the present study has some limitations. In particular, the retrospective nature of the study and a potential for era bias can be considered limitations. Additionally the sample size may be a limitation in our study. But all patients were treated in a high-volume center after being evaluated by a multidisciplinary team. Statistics were not worked. Because the number of MS and the number of collar incisions are not compatible. 
surgery

In conclusion, MS is not necessary in the treatment of ITG extending through the thoracic inlet and beneath the sternum.

\section{Acknowledgement}

We are thankful to all colleagues working for our clinic since half decade. Also many thanks to Dr. A. Sahin for the contributions to editing of the manuscript.

\section{Conflicts of Interest}

Authors declare that there is no conflict of interest with regard to this manuscript.

\section{Financial Disclosure}

The authors declared that this study has received no financial support.

\section{References}

1. Gao B, Jiang Y, Zhang X, Zhao J, He Y, Wen Y.Surgical treatment of large sub-sternal thyroid goiter; Analysis of 12 Patient. IJCE Med 2013; 6: 488-496.

2. Dogan R, Koçak I, Eren SB. Huge guatr. Turk Arch Otolaryngol 2011; 49: 40-44.

3. Yonder H, Ara C, Kacmaz O, Bozkurt S, Kaya F. Giant substernal goiter. JTOMC 2016; 23: 251-253.

4. White ML, Doherty GM, Gauger PG. Evidence-based surgical management of substernal goiter. World J Surg 2008; 32: 1285-1300.

5. Agha A, Glockzin G, Ghali N, Iesalnieks I, Schlitt HJ. Surgical treatment of substernal goiter: an analysis of 59 patients. Surg Today 2008; 38: 505-511.

6. Huins CT, Georgales C, Mehrzad H, Tolley NS. A new classification system for retrosternal goitre based on a systematic review of its complication and management. Int J Surg 2008: 6; 71-78.
7. Yorgancilar E, Yildirim M, Gün R, Bakir S, Topcu I. Substernal Guatra Yaklasim. KBB Forum 2011; 10.

8. Nistor C, Ciuche A, Motas C. Cervico-mediastinal thyroid masses-our experience. Chirurgia 2014; 109: 34-43.

9. Rugiu MG, Piemonte M. surgical approach to retrosternal goitre: do we still need sternotomy? Acta Otorhinolaryngol Ital 2009; 29: 331-338.

10. Shen WT, Kebebew E, Duh QY, Clark OH. Predictors of airway complications after thyroidectomy for substernal goiter. Arch Surg 2004; 139: 656-659.

11. Abboud B, Sleilaty G, Mallak N, Abou Zeid H, Tabchy B. Morbidity and mortality of thyroidectomy for substernal goiter. Head Neck 2010; 32: 744-749.

12. Rosato L, Avenia N, Bernante P. Complications of thyroid surgery: analysis of a multicentric study on 14, 934 patients operated on in Italy over 5 years. World J Surg 2004; 28: 271-276.

13. Gao B, Tian W, Jiang Y, Zhang X, Zhao J, Zhang S, Chen J, Luo D. Peri-operative treatment of giant nodular goiter. Int J Med Sci 2012; 9: 778-785.

14. Monchik JM, Materazzi G. The necessity for a thoracic approach in thyroid surgery. Arch Surg 2000; 135: 467-471.

15. Cohen JP. Substernal goiters and sternotomy. Laryngoscope 2009; 119: 683-688.

16. Wang $\mathrm{S}, \mathrm{Xu} \mathrm{S}$, Liu B. Resection of huge retrosternal goiter through a novel combined cervical and robot assisted approach. Artfic Organs 2014; 38: 431-433.

\section{*Correspondence to}

Menduh Oruc

Department of Thoracic Surgery

Dicle University Medical School

Turkey 